\title{
Survey of city ordinances and local enforcement regarding commercial availability of tobacco to minors in Minnesota, United States
}

\author{
Jean L Forster, Kelli A Komro, Mark Wolfson
}

\begin{abstract}
Objectives - To determine the extent and nature of local ordinances to regulate tobacco sales to minors, the level of enforcement of local and state laws concerning tobacco availability to minors, and sanctions applied as a result of enforcement.
\end{abstract}

Design-Tobacco control ordinances were collected in 1993 from 222 of the 229 cities greater than or equal to 2000 population in Minnesota, United States. In addition a telephone survey with the head of the agency responsible for enforcement of the tobacco ordinances was conducted.

Main outcome measures-Presence or absence of legislative provisions dealing with youth and tobacco, including licensure of tobacco retailers, sanctions for selling tobacco products to minors, and restrictions on cigarette vending machines, self-service merchandising, and point-of-purchase advertising; and enforcement of these laws (use of inspections and "sting" operations, and sanctions imposed on businesses and minors). Results - Almost $94 \%$ of cities required tobacco licences for retailers. However, $57 \%$ of the cities specified licences for cigarettes only. Annual licence fees ranged from $\$ 10$ to $\$ 250$, with the higher fees adopted in the previous four years. More than $25 \%$ of the cities had adopted some kind of restriction on cigarette vending machines, but only six communities had banned self-service cigarette displays. Three cities specified a minimum age for tobacco sales staff. Fewer than $25 \%$ of police officials reported having conducted compliance checks with minors or in-store observations of tobacco sales to determine if minors were being sold tobacco during the current year. Police carrying out compliance checks with youth were almost four times as likely to issue citations as those doing in-store observations. More than $90 \%$ of police reported enforcement of the law against tobacco purchase or possession by minors, and nearly $40 \%$ reported application of penalties against minors.

Conclusions - Almost $75 \%$ of the cities have done nothing to change policies or enforcement practices to encourage com- pliance with tobacco age-of-sale legis lation, and only a few of the remaining cities have adopted optimal policies. I addition, officials in Minnesota cities are much more likely to use enforcement strategies against minors who buy tobacco than against merchants who sef tobacco.

(Tobacco Control 1996; 5: 46-51)

Keywords: tobacco ordinances, enforcement; minor tobacco sales

\section{Introduction}

Onset of tobacco use primarily occurs during early adolescence, with two-thirds of ados lescents in the United States having trie smoking by age $18 .^{1}$ National surveys show that the rate of regular (monthly) smoking among high-school seniors (age 17-18) ha risen steadily since 1992 , and reached $31 \%$ in 1994 (Monitoring the Future Study press re lease, 20 July 1995: Smoking rates climb among American teenagers, who find smoking int creasingly acceptable and seriously underest mate the risks). Although school, communit and media education programmes help detêㅇ tobacco use by minors, their effectiveness appears to be seriously undermined when youth are easily able to purchase tobacco products from local businesses (Roesele Capra, and Quinn, unpublished). Tobacç availability and promotion are associated witל all stages of smoking initiation among children and adolescents, from experimentatio through addiction. ${ }^{1}$ Several national surveys of adolescents found that most young people considered it to be "very easy" or "fairlsy easy" to get cigarettes. ${ }^{1}$ The pattern evidenced in studies using self-reported data is borne out in assessments of the ability of teenagers to bu\& cigarettes. Studies reported from around the country have found over-the-counter sales tơ minors ranging from $32 \%$ to $87 \%$ and vending machine sales ranging from $82 \%$ to $100 \%{ }^{1}$ 宁

After the adoption in 1989 in Minnesota of the first city ordinance in the United State 8 that totally prohibited cigarette vending mach? ines (Forster, Hourigan, and Weigum, un 8 published), cities in Minnesota and elsewhere began to examine and upgrade their policies. and enforcement practices regarding avail ability of tobacco to minors. ${ }^{2}$ Following on the heels of the local movement, in the past five years a number of states have adopted laws designed to restrict access of tobacco to minors, 
and every state now has banned the sale of tobacco to minors. ${ }^{3}$ In July 1992, President Bill Clinton signed the Alcohol, Drug Abuse, and Mental Health Administration (ADAMHA) Reorganization Act (Public Law 102-321), one provision of which requires States to ban the sale and distribution of tobacco products to anyone under the age of 18 by 1 October 1994 (referred to as the "Synar Amendment"). It also requires states to enforce their laws in a manner that can reasonably be expected to reduce the extent to which tobacco products are available to "underage youths." Other federal action includes the recent decision of the President to request that the Food and Drug Administration regulate tobacco, including tobacco sales to minors. The proposed regulations, which have not yet been finalised, would be very far-reaching, and include a ban on self-service displays, mail order sales, vending machine sales, products that carry a tobacco product brand name or logo, and restrictions on tobacco advertising that children might encounter. ${ }^{5}$

A 1941 Minnesota statute transferred licensure authority for tobacco and other products to cities, and since then state law has permitted, but not required, cities to license tobacco retailers. State statutes have prohibited sale or provision of tobacco to minors (those under age 18) since 1913. In 1987, Minnesota became the first state to prohibit any distribution of free tobacco samples, following the earlier adoption of similar legislation by the cities of Minneapolis and St. Paul. In 1990, soon after a number of cities adopted a ban or restriction on cigarette vending machines, the Minnesota legislature passed a tobacco industry-sponsored bill which required locking devices on all cigarette vending machines except those located in businesses with alcoholic beverage licences, and specified that machines must be located within view of an employee. This law, though much weaker than desired, established a minimum standard with more stringent local ordinances permitted. In 1992, the Minnesota legislature adopted another tobacco industrysponsored measure which prohibited minors from purchasing tobacco products, but tobacco control advocates were able to amend the bill to make exceptions for research, education, training, or enforcement purposes. ${ }^{6}$

As noted above, the adoption of local ordinances regulating the distribution of tobacco to minors has increased dramatically in the past several years, at least in some states. These ordinances (which may, for example, prohibit vending machine sales or all selfservice sales of tobacco, require the tobacco sellers to be age 18 , specify civil penalties for violators of the tobacco age-of-sale law, and/or require compliance checks according to specified timetables) are representative of the new, creative responses to the tobacco access problem emerging at the local level.

As the Synar Amendment recognises, if laws are to be effective, enforcement is essential. In 1990, the US Department of Health and Human Services' Office of Inspector General found little evidence that state or local tobacco- distribution laws were being actively enforced, in a study using a limited number of informants. ${ }^{4}$ Results from preliminary studies in two communities suggest that the prevalence of tobacco use is reduced among youth in communities that have increased edircation concerning, and enforcement of, to bution laws. The major predictor of success was active, local enforcement of laws prohibiting the sale of tobacco to minors. ${ }^{7,8}$ However, no systematic data are ogvailable to document local enforcement of lofeal or statewide laws once they are adopted. $\stackrel{\square}{2}$

The objective of this study was to measure the adoption of changes in local ordinances in Minnesota (a state believed to have among the heaviest level of local activity), the level of enforcement of local and state laws concerning tobacco availability to minors, angd the type and level of sanctions applied aś-a result of enforcement. This information gifes a picture of the status of local tobacco policys documents the progress and activities that are possible, and provides guidelines for further action.

$\begin{array}{ll}\text { Methods } & \text { Oे } \\ \text { SURVEY POPULATION } & \overrightarrow{0} \\ \text { All }\end{array}$

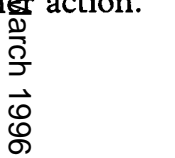

All Minnesota cities with a populapion of 2000 or more according to the 1990 US scensus were included in the study, for a total off 229 cities. The size criterion was applied bece smaller cities may not have their own pol $\$$ rely on staff from other jurisdictions for law enforcement, and because most retail tobacco outlets are located in these larger chies. Almost $50 \%$ of the cities in this sup.vey had a population of less than 5000, and क्रुother $40 \%$ had between 5000 and 25000 . About $54 \%$ of the cities were within the Mimneapolis-St Paul metropolitan area. Officials from seven cities did not respond, yielding a final sample of 222 cities and a response rate $97 \%$.

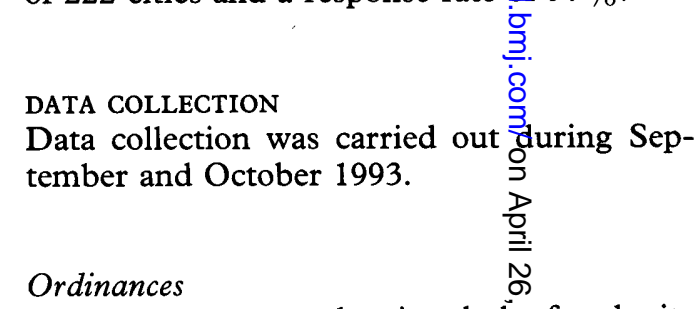

A letter was sent to the city clerkifof each city requesting a copy of all ordinanges having to do with tobacco control. A list of Epics related to tobacco was included in the Jetter. These ordinances were coded by a single foder for the presence or absence of provisions thaving to do with youth and tobacco. Thes@ provisions included whether or not a tobacc licence was required; amount of licence fee\& whether or not licences could be suspended of revoked for selling tobacco to minors; wheth or not fines were specified for those violatingghat law; the type of cigarette vending machin restriction, if any; if tobacco could only be di pensed by an employee (no self-service merchandising); whether any restrictions on point-of-purchase advertising were in place; and any other ordinances having to do with youth and tobacco. The date of adoption and implemen- 
tation was recorded for each ordinance. Follow-up telephone calls were made to the city clerk as needed to complete information not available in the ordinance, such as current licence fees or dates of ordinance implementation. The number of tobacco licences, if applicable, in each city was obtained from the city clerk as well.

\section{Enforcement}

City clerks were also asked which agency provided law enforcement for their city. A telephone interview was conducted with the head of that agency, or the individual they designated as the person most knowledgeable about enforcing tobacco age-of-sale laws in their city. Respondents were asked if (and when the last) inspections had been done to determine the licensees' compliance with state and city vending machine laws; whether or not any "sting" operations (underage purchase attempts supervised by police) had been carried out, and if yes, how many businesses had been cited, fined, and/or had licences suspended; whether in-store observations had been used to enforce the law against tobacco sales to minors, and the results of these efforts; and whether minors had been warned, cited, fined, and/or arrested for using tobacco. As many individuals were contacted as necessary to obtain complete information about enforcement and subsequent action. The survey was pretested in Minnesota cities with a population of less than 2000 and in several Wisconsin cities, and was carried out by trained survey interviewers at the Telephone Survey Center of the Division of Epidemiology.

\section{DATA ANALYSIS}

Frequencies were calculated for each type of ordinance, surveillance activity, and enforcement activity for all 222 cities and by population of city $(5000, \mathrm{n}=107 ; 5000-25000$, $\mathrm{n}=88$; > 25000, $\mathrm{n}=27$ ).

\section{Results}

ORDINANCES

Licensing

As table 1 indicates, almost $94 \%$ of cities required some kind of tobacco licence for retailers. However, only $37 \%$ required licences for all types of tobacco, whereas the ordinance in the remaining $57 \%$ of the cities specified licences for cigarette sales only. Compreher" sive licence requirements (applying to bot cigarettes and smokeless tobacco) were leaf common in smaller communities. Large $\overline{\bar{n}}$, metropolitan communities were most likely lack any licence requirements altogether; hows ever, when large cities did report a licence requirement it was likely to apply to all tobacco products. Four cities adopted licensing ordiñ ances for the first time since 1989, when the current wave of local action concerning policies to restrict youth access to tobacco began.

Just over 200 city clerks responded to the question about how many tobacco licences were held in the city; of these $49 \%$ reported $1 \underline{16}$ or fewer total licences. The range reported was 1-2023 licences. However, some cities requirê용 a separate licence for each vending machine, whereas others allowed multiple machines $\vec{\theta}$ be operated under one licence. Only about 15 of the 222 cities in the sample could distinguisib between vending machine or over-the-counteif businesses among their licensees. Of thes $30 \%$ reported no vending machines.

Annual licence fees ranged from $\$ 10$ $\$ 250$, with $\$ 12$ specified by $41 \%$ of the cities an amount dating back to the early 1940 S when licensure authority was transferred to cities. Smaller communities were more like to have low licence fees. In more than $50 \%$ क्f the cities, licence fees were not set by of dinance, but annually by city council res olution, making them easier to change. Si cities charged higher fees for vending machine licences than over-the-counter licences.

Many cities had incorporated the option apply a civil penalty to businesses that sefl tobacco to minors. Civil penalties (fines, li@ ence suspensions or revocations) are applied without involving the court system, much \& traffic violations are handled, thus makin enforcement easier and more likely to occuㄹ. More than $40 \%$ of the licensing ordinances?

Table 1 Percentage of cities with specific ordinances concerning tobacco availability to minors

\begin{tabular}{|c|c|c|c|c|}
\hline \multirow[b]{2}{*}{ Ordinance } & \multirow[b]{2}{*}{$\begin{array}{c}\text { All cities }(\%) \\
(n=222)\end{array}$} & \multicolumn{3}{|c|}{ City population $(\%)$} \\
\hline & & $\begin{array}{c}<5000 \\
(n=107)\end{array}$ & $\begin{array}{c}5000- \\
25000 \\
(n=88)\end{array}$ & $\begin{array}{l}>2500 \\
(n=27\end{array}$ \\
\hline \multicolumn{5}{|l|}{ Licence } \\
\hline City licence for all tobacco products & 36.5 & 28.0 & 44.3 & 44.4 \\
\hline City licence for cigarettes only & 57.2 & 69.2 & 45.5 & 48.2 \\
\hline No tobacco licence required & 6.3 & 3.8 & 10.1 & 7.3 \\
\hline \multicolumn{5}{|l|}{ Annual Licence Fee ${ }^{\star}$} \\
\hline$<\$ 25$ & 68.3 & 78.2 & 63.2 & 41.7 \\
\hline$\$ 25-100$ & 29.2 & 20.6 & 35.5 & 45.8 \\
\hline$>\$ 100$ & 2.5 & 1.0 & 1.3 & 12.5 \\
\hline Suspension of licence for selling tobacco to minors & 41.9 & 50.5 & 27.3 & 55.6 \\
\hline Fine for selling tobacco to minors & 1.4 & 0.9 & 1.1 & 3.7 \\
\hline \multicolumn{5}{|l|}{ Vending machine } \\
\hline Total ban & 9.0 & 5.6 & 5.7 & 33.3 \\
\hline Partial restrictions & 16.7 & 10.3 & 21.6 & 25.9 \\
\hline Restrict display & 2.7 & 0.9 & 3.4 & 7.4 \\
\hline Restrict seller age & 1.4 & 1.9 & 1.1 & 0.0 \\
\hline
\end{tabular}

$\star \mathrm{n}=202 ; 14$ Cities do not require licences for tobacco; information on amount of fee was unavailable for six communities. 
Table 2 Percentage of cities that have conducted surveillance of merchant compliance with the state age-of-sale law within the current year

\begin{tabular}{lcccc}
\hline & & \multicolumn{3}{c}{ City population (\%) } \\
\cline { 3 - 5 } & All cities $(\%)$ & $<5000$ & $\begin{array}{c}5000- \\
25000\end{array}$ & $>25000$ \\
$(n=222)$ & $(n=107)$ & $(n=88)$ & $(n=27)$ \\
\hline Activity & 7.2 & 3.7 & 5.7 & 25.9 \\
Compliance checks with youth & 17.6 & 17.8 & 17.0 & 18.5 \\
\hline
\end{tabular}

permitted licence suspension, and in all but six cities the city council decided the length of suspension. Six of those were passed since 1989. Three cities specified fines for licensees caught selling tobacco to minors.

\section{Restrictions on vending machine sales of cigarettes}

Fifty-seven cities $(26 \%)$ had some kind of ordinance restricting vending machine location, including 20 that had adopted a total ban on cigarette vending machines. Small cities were more likely to have no restrictions, whereas most of the 27 cities with a population of 25000 or more had adopted some kind of restriction, usually a total ban. Of the 37 cities with partial restrictions on cigarette vending machines, 35 restricted the placement of the machine, 15 required locking devices on some or all machines, and 16 restricted the type of business where a vending machine could be located. All of the total bans and more than $90 \%$ of the partial restrictions on vending machines were adopted since 1989.

\section{Other ordinances to restrict minors' access to tobacco}

Six communities banned self-service cigarettes sales (required that tobacco be displayed behind a counter and dispensed by an employee) at least for single packs, and three cities restricted the age of individuals who may sell tobacco. All of these provisions were new since 1989. In addition, five cities required a sign specifying the tobacco age of sale in each business, and three prohibited tobacco sales within $30-90 \mathrm{~m}$ (100-300 feet) of a school.

\section{ENFORCEMENT}

Compliance with vending machine laws and ordinances

In cities with a restrictive vending machine ordinance, police officials were asked whether they performed inspections to deteemine compliance with the local ordinance. जWhere no local ordinance existed, officials Were asked

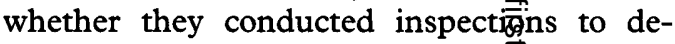
termine compliance with the Minpesota state vending machine law which requites locking devices on machines not in liquors establishments and placement of machines githin view of an employee. Just under $57 \%$ of officials from cities with restrictive vending machine ordinances (but not total bans) reported performing inspections compared with $37 \%$ of officials from cities with no localordinance. Those with total vending machine्ध bans were less likely to report inspections $(30 \%)$ compared with cities with no local venditg machine ordinance.

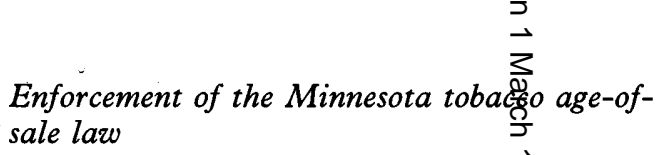

As table 2 shows, fewer than 25 of police officials reported having conductedany kind of surveillance during the current year, to determine if tobacco was being soldsto minors. Fewer than $30 \%$ of these surveillane activities were compliance checks, using a然 underage undercover buyer to check for com liance with the law, with the remainder beigng in-store observations by enforcement officts. Larger cities ( $>25000$ population) were Tuch more likely to have carried out compliañce checks. In more than $80 \%$ of the cases these enforcement actions were carried out supervision. Other cities reporte $\mathbb{\$}$ that they were carried out by communityo drug task forces, the city licensing department, or the city advisory board of health.

으

Table 3 reports penalties applie as a result of enforcement activities. Of the 1 cities that have carried out compliance check during the current year, $25 \%$ reported that businesses had been fined for selling tobacco to minors (average $=6.7$ businesses), and 19\% reported

Table 3 Percentage of cities that have taken action against merchants or minors for violations of lawsinertaining to tobacco and minors

\begin{tabular}{|c|c|c|c|c|c|}
\hline \multirow[b]{2}{*}{ Activity } & \multirow[b]{2}{*}{$\begin{array}{l}\text { All cities }(\%) \\
\quad(n=222)\end{array}$} & \multicolumn{4}{|c|}{ City population (安) } \\
\hline & & $\begin{array}{c}<5000 \\
(n=107)\end{array}$ & $\begin{array}{c}5000- \\
25000 \\
(n=88)\end{array}$ & 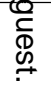 & $\begin{array}{l}>25000 \\
(n=27)\end{array}$ \\
\hline \multirow{2}{*}{\multicolumn{6}{|c|}{$\begin{array}{l}\text { Actions against merchants } \\
\text { All cities }\end{array}$}} \\
\hline $\begin{array}{l}\text { All cities } \\
\text { Any penalty }\end{array}$ & & & & (จ) & \\
\hline $\begin{array}{l}\text { Any penalty } \\
\text { Fines }\end{array}$ & 0.3 & 1.9 & 0.8 & $\stackrel{\rho}{\rho}$ & 22.2 \\
\hline Suspended licence & $\begin{array}{l}4.5 \\
2.7\end{array}$ & $\begin{array}{l}0.9 \\
0.9\end{array}$ & 6.8 & @̊ & 11.1 \\
\hline \multicolumn{6}{|c|}{ Cities that conducted compliance checks $(n=16)$} \\
\hline Any penalty & 37.5 & 25.0 & 40.0 & & 42.9 \\
\hline Fines & 25.0 & 0.0 & 40.0 & రి & 28.6 \\
\hline Suspended licence & 18.8 & 25.0 & 20.0 & 므 & 14.3 \\
\hline \multicolumn{6}{|c|}{ Cities that conducted in-store observations $(n=39)$} \\
\hline Any penalty & 10.3 & 5.3 & 13.3 & 트 & 20.0 \\
\hline Fines & 10.3 & 5.3 & 13.3 & $\underset{\rightleftarrows}{\rightleftharpoons}$ & 20.0 \\
\hline Suspended licence & 0.0 & 0.0 & 0.0 & & 0.0 \\
\hline \multicolumn{6}{|l|}{ Actions against minors } \\
\hline Either warned or penalised minors & 90.1 & 88.8 & 89.8 & & 96.3 \\
\hline Warned minors & 87.4 & 86.9 & 86.4 & & 92.6 \\
\hline Penalised minors & 39.6 & 26.2 & 47.7 & & 66.7 \\
\hline
\end{tabular}


that tobacco licences had been suspended (average $=3.5$ businesses).

Of those not carrying out compliance checks, another 39 reported doing in-store observations of tobacco sales during the current year, to determine if minors were being sold tobacco. As a result of these observations, $10 \%$ of the 39 cities reported issuing fines to businesses (average $=1.8$ business) for selling to minors, and none reported suspending any tobacco licences. These inspections were almost exclusively carried out by police officers.

\section{Enforcement of the Minnesota law against tobacco purchase/possession by minors} In 1992, the Minnesota legislature passed a law against the purchase, attempt to purchase, or possession of tobacco by minors, unless under adult supervision for purposes of education, surveillance, research, or training. As table 3 shows, more than $90 \%$ of cities report some action to enforce this law against minors, and nearly $40 \%$ reported application of serious penalties.

\section{Discussion}

Results of this study should be interpreted with attention to the limitations of the study design. This study represents one state at one point in time. It gives a snapshot of what was happening in Minnesota in 1993. Although we surveyed the law enforcement officer charged with enforcement in each city, their reports of enforcement activity and results of enforcement (citations, penalties) were not verified.

In Minnesota, unlike some other states, the most meaningful changes in policy and practice to reduce youth access to tobacco have occurred at the local level. Between 1989 (when this wave of policy change began in Minnesota) and 1993 , more than $25 \%$ of the cities with a population greater than 2000 made some policy changes. With a few exceptions, policy changes were largely self-initiated and are likely to reflect a natural diffusion process in which cities look to their neighbours for leadership and ideas on new issues. Although efforts have been mounted by the statewide tobacco control coalition to strengthen state laws, the major success at the state level has been to prevent tobacco industry-initiated policies, such as pre-emption of local tobacco control ordinances, from being adopted. Similarly, enforcement of state or local laws to restrict youth access to tobacco has occurred entirely at the local level.

Regardless of the progress that has been made to enact local ordinances in Minnesota communities and other locations, access to tobacco will not be restricted unless these laws are enforced. Fewer than $25 \%$ of police officials reported any efforts during the current year to determine if stores were making illegal sales. Most of the efforts that did occur were in-store observations by police officers, which this study shows are less likely to result in a citation than compliance checks with young purchasers. In addition, locally generated vending machine ordinances were more likely to be enforced than the statewide law.

Police indicate that one barrier to enforcement is that the state tobacco age-of-sale last specifies criminal penalties against the sale staff, which are considered draconian, with penalties against the licence holder. A possibfe remedy is for local communities to adopt licensing ordinances that include civil penaltis (administrative fines or licence suspension against the licensee. It was a surprise to fiwd from this survey that a large proportion $\overline{\overline{\bar{g}}}$ cities already have a civil penalty in the licensing ordinances, which predates the recemt wave of tobacco policy changes. This older civil penalty was almost always licence suspension, which was rarely enforced. Morte recent recommendations are for a graduated penalty system beginning with relatively smâ1 fines to encourage compliance, with licence suspension or revocation used as a last resolit.

Another barrier often cited is the expense associated with enforcement. Licence fees căn be used to cover these costs, and state law indicates that licence fees should reflect thes costs. This survey shows that most licence fees have not been updated for decades, and that larger licence fees are clearly feasible, indicated by the number of cities with fees over $\$ 25$ per year.

Possibly the most striking and alarmi result to come from this study is that polige were overwhelmingly more likely to enforge the laws against minors and more likely penalise minors compared with merchan More than $90 \%$ of cities reported some action to enforce the law against tobacco purchaşe, possession, or use by minors, and more that $40 \%$ reported application of serious penalti This is especially noteworthy compared with the $25 \%$ of cities that reported some expforcement action against merchants for selli tobacco to minors, and less than $10 \%$ where penalties were applied. These results consistent with reports from Utah and South Dakota, where minors are reportedly sele्ctively targeted. ${ }^{9}$ The same pattern has been observed in enforcement of alcohol minimumage-of-sale laws, where nationally the arrest rate for minors using alcohol is more than 40 times the arrest rate for merchants selliwg alcohol to minors. ${ }^{10}$ Clearly police officials find it easier to launch enforcement efforts againgst minors compared with merchants, and much more likely to define the problem $\delta f$ youth tobacco use in terms of juvenile offenters than adult providers. This disproportionate use of enforcement resources supports twe arguments of many tobacco control advocaes against laws that penalise minors for purch and possession of tobacco. ${ }^{11,12}$

Although many cities have developed mes ingful and creative policies and practices go restrict youth access to tobacco since the 1 iate 1980 s, most cities have yet to respond to thins challenge and opportunity. Even in Minneso where the movement to address youth access has been strong relative to many other states, almost $75 \%$ of the cities had done nothing by 1993 to change policies or enforcement prac- 
tices to encourage compliance with the tobacco age-of-sale law, and only a few of the remaining cities had adopted optimal policies. This lack of local action argues in favour of a dual emphasis on strong state laws as well as local ordinances that require licensing, include civil penalties, require compliance checks, and address self-service merchandising. There are advantages to locally generated policies: the tobacco industry has less influence over the local policy process; locally negotiated policies may inspire stronger support and ownership on the part of citizens and officials; police may be more likely to enforce local ordinances, as our data on vending machine laws illustrate; and each city represents an independent opportunity for tobacco control activists when stymied at the state level.

However the slowness and inefficiency of the diffusion process and the likelihood that less than optimal policies will result speak to the need for continued pressure for strong statewide laws and action at the federal level that do not pre-empt more restrictive local ordinances. That is, cities must be allowed to continue to innovate and develop more restrictive policies against the backdrop of meaningful state and federal regulations. Regulations and discussion which result from the Synar Amendment and the Food and Drug Administration proposals tend to stimulate and support local action, unlike pre-emptive laws which a number of states have adopted. Tobacco control advocates must carefully consider the opportunities to advance state policy to restrict youth access without pre-empting the efforts of cities to create new responses to this problem.

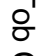

1 US Department of Health and Human Servises. Preventing tobacco use among young people. A repor ${ }^{\circ}$ the Surgeon General. Atlanta, Georgia: Public Healtp Service, Centers for Disease Control and Prevention, Office on Smoking and Health, 1994. (US Gover

2 US Department of Health and Human SeWices. Smoking and tobacco control monograph 3: majg local tobacco control ordinances in the United States. Buthesda, Maryland: Public Health Service, Nationaf Institutes of Health, 1993. (NIH Publication No. 93-\$532.)

3 US Centers for Disease Control and Pretention. State tobacco control highlights-1996. Atlqtia, Georgia: Centers for Disease Control and Prevention, Office on Smoking and Health, 1996. (CDC Publigtion No 0994895.)

4 US Department of Health and Human Services, Office of Inspector General. Youth access to tobgyco. Bethesda, Maryland: Department of Health and Human Services, Public Health Service, National Institues of Health, 1992. (NIH Publication No. OEI-02-91-00880.)

5 Statements by President Bill Clinton and the US Food and Drug Administration on regulations restrict the marketing, sale and distribution of tobaęo to children. Tobacco Control 1995; 4: 299-309. 을

6 Minn. Statues Annot., 1992, Sect. 609.685, 325E.07, 325E.075.

7 Jason LA, Ji PY, Anes MD, Birkhea SH. Active enforcement of cigarette control laws in the prevention of cigarette sales to minors. $\mathscr{F} A M A 1991$; 260 : 3159-61.

8 Difranza JR, Carlson RR, Caisse RE. Reducing youth access to tobacco. Tobacco Control 1992; $\mathrm{Tt}: 58$.

9 Proposed rules. Federal Register 1993; 58: 169

10 Wagenaar AC, Wolfson M. Enforcement of the legal minimum drinking age in the United Etates. I Public Health Policy; 15: 37-53.

11 Institute of Medicine. Growing up tobacco nicotine addiction in children and youth Washington, DC: National Academy Press, 1994.

12 Carol J. It's a good idea to criminalizếpurchase and possession of tobacco by minors - not! Gobacco Control 1992; 1: 296-7. 